\title{
Occupational factors related to shoulder pain and disability
}

\author{
Daniel P Pope, Peter R Croft, Christina M Pritchard, Alan J Silman, Gary J Macfarlane
}

\begin{abstract}
Objectives-To determine, in a population based study, the influence of occupational factors on the occurrence of shoulder pain and disability.

Methods-A random sample of patients was selected from the register of a general practice in the Greater Manchester area of the United Kingdom. Information was collected by a posted questionnaire with specific enquiries about symptoms in the shoulder region and related disability. A lifetime occupational history was obtained including physical exposures, working conditions, and psychosocial aspects of each workplace. Analysis has been conducted as a case-control study, comparing occupational exposures at the time of onset of symptoms in those with shoulder pain and disability with corresponding occupational exposures in those without shoulder pain and disability.
\end{abstract}

Results-An increased risk of shoulder pain and disability in men was associated with carrying weights on one shoulder (relative risk (RR) 5.5, 95\% confidence interval (95\% CI) 1.8 to 17$)$, whereas those who reported working with hands above shoulder level, using wrists or arms in a repetitive way, or stretching down to reach below knee level had about twice the risk of shoulder pain and disability. Men working frequently in very cold or damp conditions had a fourfold and sixfold risk respectively of shoulder pain and disability. Reporting of shoulder pain and disability was also more common among men and women who reported that their work caused a lot of stress (RR 1.9, 95\% CI 0.9 to $4 \cdot 1$ ) or was very monotonous ( $R R$ 2.7, 95\% CI 1.3 to 5.4). The relations between physical exposures, working conditions, and psychosocial factors were independent.

Conclusions-This population based study has shown that physical activities carried out at work, the physical conditions under which the work is conducted, psychosocial aspects of work, or the working environment are all independently related to the occurrence of shoulder symptoms and disability, emphasising the multifactorial nature of this condition.

(Occup Environ Med 1997;54:316-321)

Keywords: shoulder pain; occupational; epidemiology
Musculoskeletal disorders of the shoulder are relatively common in the general population but are considered to be usually short lived and not incapacitating. ${ }^{1}$ However, measuring the prevalence of shoulder disorders is difficult given that estimates are highly dependent on the precise definition used. In the Health and Nutrition Examination Survey I, conducted in the United States, a prevalence estimate for shoulder symptoms of $7 \%$ was derived from a sample of 6913 adults with a definition of "at least one month of musculoskeletal pain in the shoulder". ${ }^{2}$ Considerably higher estimates of the occurrence of shoulder symptoms have been found in studies of occupational groups. Silverstein ${ }^{3}$ studied 574 workers in six manufacturing plants in the United States and reported a prevalence of $33 \%$ for neck or shoulder pain "occurring more than once or lasting more than one week in the last two years". Similarly high estimates have been found in other occupational settings. Occupational factors which have been associated with musculoskeletal symptoms in the shoulder relate to both physical aspects of the work undertaken as well as psychosocial factors concerning work and the working environment. Aspects of work thought to increase the risk of symptoms include physically heavy work, working with arms at or above shoulder level, repetitive movements of the arms, and lack of sufficient rest. ${ }^{4}$ Occupations which are monotonous, involve time pressure, or high workload with little personal autonomy have also been found to have an increased prevalence of musculoskeletal symptoms. ${ }^{5}$

The current study is one of a few to use population based data to examine the influence of occupational factors related to shoulder pain and disability. It examines the influence of work tasks carried out, physical working conditions, and psychosocial aspects of work, on the occurrence of shoulder pain.

\section{Methods}

The study population comprised 500 people, randomly selected from the register of one general practice in the Greater Manchester area of the United Kingdom. The sample was stratified by age and sex, reflecting the demographic characteristics of the area. A questionnaire was posted to the sample selected, and included items on the experience of pain during the past month, as well as specific enquiries about symptoms in the shoulder region. All respondents to the questionnaire were then contacted either by telephone or post and per- 
mission to interview them was sought. At interview the information collected about shoulder symptoms included whether subjects had experienced shoulder pain (pain in the area delineated in the figure) lasting for at least 24 hours in the month before interview, and whether they still had shoulder pain at the time of interview. Subjects with shoulder pain were asked to complete a short, 23 item, questionnaire enquiring about disability in daily living associated with such symptoms. This questionnaire was developed from the Functional Limitations Profile $^{6}$ and has been validated in general practice and in the community. ${ }^{7}$ Topics covered by the questionnaire include domestic, recreational, and psychosocial problems relating to shoulder symptoms.

As well as information on shoulder pain and disability, data were obtained on the current job, and all previous jobs which the respondent had held. For each job, the age at starting and finishing, working conditions, occupational activities, and postures adopted were recorded. Occupational activity items were preceded by the question "On an average working day do you do any of the following on at least two days per week regularly?" thereafter a list of individual activities was givenfor example, lift or carry weights of more than $25 \mathrm{lb}$, and answers were recorded on a dichotomous scale (yes or no). Subjects were asked how often they experienced various physical working conditions-for example, working in moist or damp conditions-or psychosocial factors - for example, work causing a lot of stress and worry-with responses recorded on a four point scale (never, occasionally, most of the time, always). These items had been successfully used in a previous population based study. ${ }^{8}$ To minimise recall bias the complete occupational history was taken separately from and before any questions on shoulder pain were asked.

\section{DEFINITION OF SHOULDER PAIN}

For the purposes of analysis subjects were classified as having shoulder pain if (a) they reported shoulder symptoms (within the area
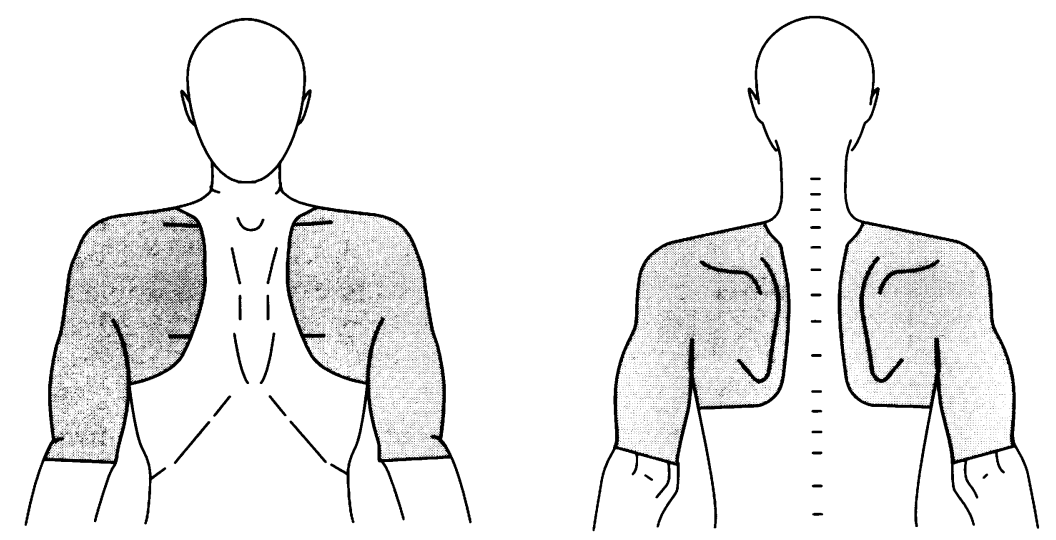

Anatomical area used in the definition of shoulder pain. shown on the figure) which had been present for at least a 24 hour period during the month before the interview, (b) had shoulder pain at the time of interview, and $(c)$ had at least one disability resulting from shoulder symptoms as assessed by the disability questionnaire used. ${ }^{7}$ This definition incorporating both pain and disability was chosen to exclude those with either transient or relatively mild shoulder pain. Hereafter the term shoulder pain will be used to define those meeting the above criteria.

\section{STATISTICAL ANALYSIS}

The relation between aspects of work and the working environment to shoulder pain has been examined by comparing occupational exposures at the time of onset of symptoms in those with shoulder pain with corresponding occupational exposures in those without shoulder pain. The analysis has been conducted with a case-control method of analysis. Cases were those with current shoulder pain as already defined, whereas controls were all other subjects in the sample. Accordingly the control group included those with no shoulder pain, transient shoulder pain, and those with shoulder pain but without any resulting disability. For each case, the time since onset of the current shoulder problem was recorded, and from the occupational history the occupation at that time was identified. For the purpose of defining time of onset of current shoulder symptoms, episodes of shoulder pain were defined as continuous if a period without any symptoms had lasted for less than one year. Thus for example, if shoulder pain had been experienced episodically over five years, but without a one year symptom free interval, the time of onset was defined as five years ago. If alternatively there had been a one year pain free period, time of onset was the time since onset of the most recent episode. Controls were randomly chosen from sets matched to cases by sex and age group (18-39, 40-59, $\geqslant 60$ years), with a variable matching ratio of, on average, $5: 1$ for men and $4: 1$ for women. The comparison occupation used for the control was the occupation being performed at a reference date. The reference date was determined by subtracting from the date of interview the "time since onset" of shoulder problems of the matched case.

Logistic regression was used to estimate the odds of disease associated with a given exposure relative to the odds of disease associated with absence of the same exposure (odds ratio (OR)). Given, however, that shoulder symptoms commonly occur in the population, the OR may not be a reliable estimate of the relative risk - that is, the risk in the exposed group relative to that in the non-exposed group. The ORs obtained have therefore been converted to risk ratios (or relative risks (RRs)) by the method of Osborne and Cattaruzza. ${ }^{9}$ Risks are presented together with $95 \%$ confidence intervals (95\% CIs); when risks are not presented separately for men and women, they have also been adjusted for sex. All analyses were conducted with the statistical package Stata. ${ }^{10}$ 
Table 1 Physical activities at work in relation to shoulder pain and disability

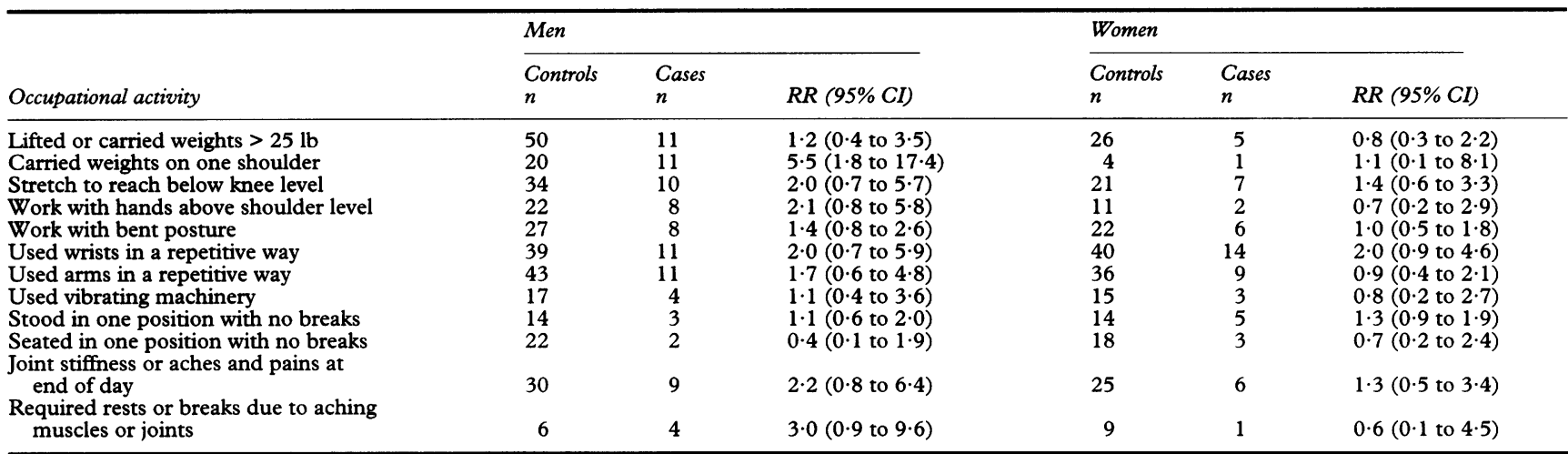

\section{Results}

In total, 312 of the original sample $(n=500)$ responded to the postal questionnaire. After excluding people who did not receive the questionnaire because they were no longer resident at the address recorded on the general practitioner's register $(n=29)$ the overall response to the survey was $66 \%$. Of the 312 respondents, $232(74 \%)$ agreed to an interview by a research nurse which was conducted at a median (range) of nine (2-23) months after the initial survey; 217 of these subjects were in employment on their reference date. These 217 formed the group for analysis in the current manuscript; 39 of whom satisfied the previously defined criteria for shoulder pain. Those with shoulder pain were older (mean age $48 v$ 45 years), more likely to report a long standing illness or disability ( $44 \% v 23 \%$ ), to have consulted a doctor about a back problem $(41 \% v$ $24 \%$ ), to have had neck pain in the past year (63\% v 40\%), and to have reported other joint problems $(87 \% v 68 \%)$ than those without shoulder pain. The percentage of men and women in both groups was similar. Among those with shoulder pain, the median (interquartile range) duration of symptoms was three (1-10) years and the most common disabilities reported were "having to change posi- tion often in bed" (80\%), "difficulty carrying things" (59\%), and "sleeping less well" (58\%).

\section{WORKING ACTIVITIES}

Among men, the work activity associated with the largest increase in risk was carrying weights on one shoulder (RR 5.5, 95\% CI $1 \cdot 8$ to $17 \cdot 4$ ). Those who reported having to take rests due to aching muscles or joints (RR 3.0, 95\% CI 0.9 to 9.6) or having aches and pains at the end of a shift (RR 2.2, 95\% CI 0.8 to 6.4 ) also had an increased risk of shoulder pain. Those men reporting "working with hands above shoulder level", "using wrists in a repetitive way", "using arms in a repetitive way", or "stretching down to reach below knee level" had about twice the risk of shoulder pain than those not reporting these activities, although these increased risks were not significant. Finally there was only a modestly increased risk associated with lifting or carrying weights of more than $25 \mathrm{lb}$ (RR 1.2, 95\% CI 0.4 to 3.5$)$ and no increased risk associated with using vibrating machinery (table 1).

Among women there were no significantly increased risks associated with any of the physical activities recorded, the highest risk being for "using wrists in a repetitive way" (RR 2.0, $95 \%$ CI 0.9 to $4 \cdot 6$ ).

Table 2 Working conditions in relation to shoulder pain and disability

\begin{tabular}{|c|c|c|c|c|c|c|}
\hline \multirow[b]{2}{*}{ Occupational conditions } & \multicolumn{3}{|l|}{ Men } & \multicolumn{3}{|l|}{ Women } \\
\hline & $\begin{array}{l}\text { Controls } \\
n\end{array}$ & $\begin{array}{l}\text { Cases } \\
n\end{array}$ & $R R(95 \% C I)$ & $\begin{array}{l}\text { Controls } \\
n\end{array}$ & $\begin{array}{l}\text { Cases } \\
n\end{array}$ & $R R(95 \% C I)$ \\
\hline \multicolumn{7}{|l|}{ Damp: } \\
\hline Never & 56 & 5 & Reference & 95 & 20 & Reference \\
\hline Occasional & 16 & 6 & $3.3(1.0$ to 11$)$ & 5 & 2 & $1 \cdot 1(0 \cdot 2$ to $5 \cdot 1)$ \\
\hline Always` & 6 & 5 & $5.4(1.6$ to 19$)$ & 0 & 1 & $3.3(0.4$ to 27$)$ \\
\hline \multicolumn{7}{|l|}{ Cold: } \\
\hline Never & 54 & 7 & Reference & 85 & 19 & Reference \\
\hline Occasional & 23 & 6 & $1.8(0.6$ to $5 \cdot 4)$ & 11 & 3 & $1 \cdot 4(0.4$ to $5 \cdot 1)$ \\
\hline Always & 1 & 3 & $6.4(1.5$ to 27$)$ & 4 & 1 & $1.1(0.2$ to 8.5$)$ \\
\hline \multicolumn{7}{|l|}{ Hot: } \\
\hline Never & 50 & 8 & Reference & 77 & 14 & Reference \\
\hline $\begin{array}{l}\text { Occasional } \\
\text { Always }\end{array}$ & 20 & 4 & $1 \cdot 3(0.4$ to $4 \cdot 2)$ & 11 & 5 & $1.9(0.7$ to 5.4$)$ \\
\hline $\begin{array}{l}\text { Always } \\
\text { Dusty: }\end{array}$ & 8 & 4 & $2.4(0.7$ to 7.9$)$ & 12 & 4 & $1.5(0.5$ to 4.5$)$ \\
\hline \multicolumn{7}{|l|}{ Dusty: } \\
\hline $\begin{array}{l}\text { Never } \\
\text { Occasional }\end{array}$ & $\begin{array}{l}51 \\
14\end{array}$ & 8 & Reference & 81 & 15 & Reference \\
\hline $\begin{array}{l}\text { Occasional } \\
\text { Always }\end{array}$ & $\begin{array}{l}14 \\
14\end{array}$ & 4 & $1.6(0.5$ to 5.4$)$ & 8 & 4 & $1.8(0.6$ to 5.5$)$ \\
\hline $\begin{array}{l}\text { Always } \\
\text { Noisy: }\end{array}$ & & 4 & $1.6(0.5$ to 5.3$)$ & 11 & 4 & $1.6(0.5$ to 4.9$)$ \\
\hline Never & 41 & 8 & Reference & 68 & 15 & Reference \\
\hline Occasional & 27 & 2 & $0.4(0.1$ to 1.9$)$ & 11 & 3 & $1.3(0.4$ to 4.8$)$ \\
\hline Always & 11 & 6 & $2 \cdot 2(0.7$ to 6.5$)$ & 21 & 5 & $0.9(0.3$ to 2.5$)$ \\
\hline \multicolumn{7}{|l|}{ Fumes: } \\
\hline $\begin{array}{l}\text { Never } \\
\text { Occasional }\end{array}$ & $\begin{array}{l}50 \\
19\end{array}$ & 11 & Reference & 90 & 22 & Reference \\
\hline Always & 10 & 2 & $\begin{array}{l}0.7(0.2 \text { to } 2 \cdot 7) \\
0.9(0.2 \text { to } 4 \cdot 1)\end{array}$ & $\begin{array}{l}4 \\
6\end{array}$ & 1 & $0.9(0.1$ to $7 \cdot 2)$ \\
\hline
\end{tabular}




\section{Working conditions}

Men working in cold or in damp conditions had an increased risk of shoulder pain. For those working most of the time or always in damp conditions the risk of shoulder pain was increased more than fivefold (RR 5.4, 95\% CI 1.6 to 19.0 ) and in cold conditions the risk was increased over sixfold (RR 6.4, 95\% CI 1.5 to $27 \cdot 0$ ). Risk of shoulder pain was also increased, although to a lesser extent, among those men exposed to cold or damp conditions occasionally or for half working time (table 2). No significantly increased risk was associated with women working in such conditions. The risk of shoulder pain was not significantly increased, as might be expected, by working in noisy or dusty conditions, nor by working with fumes. For men there was an increase in risk, although not significant, associated with working in very hot conditions (RR $2 \cdot 4,95 \%$ CI 0.7 to 7.9 ). These relations were not confounded by the specific tasks being carried out, with little change in the risk estimates when assessed together in the same logistic regression model.

\section{PSYCHOSOCIAL ASPECTS OF WORK}

Reporting of shoulder pain was more common among those people who reported that their work caused a lot of stress or worry either most of the time or always (RR $1.9,95 \%$ CI 0.9 to $4 \cdot 1)$. Similarly an increased risk was noted among those whose work was monotonous ( $R R 2 \cdot 7,95 \%$ CI 1.3 to $5 \cdot 4$ ). In both instances the size of the risk was the same for both men and women. The size of risks remain unchanged after adjustment, in the logistic regression model, for the actual tasks being undertaken, and the working conditions.

\section{Discussion}

This is a small population based study of shoulder pain and disability intended to generate hypotheses about occupational factors, both physical and non-physical, that may increase the risk of symptoms. The results suggest that shoulder pain and disability are associated with several aspects of employment: working conditions, working activities, and psychological aspects of work. Risks associated with both working conditions and activities were primarily confined to men. Working with hands above shoulder level, using wrists in a repetitive way, stretching down below knee level, and working with bent posture all resulted in a risk at least double those not exposed to such activities, whereas regularly working in damp or cold conditions or carrying weights on one shoulder increased the risk about fivefold. Among women there was little variation in the risks of shoulder pain according to working conditions or activities.

The associations of shoulder pain with carrying weights on one shoulder and working with hands at or above shoulder level have been reported previously, with both showing a dose-risk relation between weight carried and time exposed respectively. ${ }^{11-13}$ Whether repetitive arm movements are a risk factor for shoul- der pain has been more controversial, ${ }^{12} 14$ although Kvarnstrom ${ }^{15}$ found that cases of occupational cervicobrachial disorder, which has shoulder pain as one of its symptoms, was concentrated among workers whose jobs involved short cycles irrespective of the actual physical load of the job. Our study supports the body of evidence suggesting that using vibrating machinery does not result in an increased risk of shoulder symptoms, ${ }^{16}$ although such a relation has been previously suggested. ${ }^{17}$ As well as these physical exposures, the present study has also reported for the first time that the working environment can have an influence on shoulder symptoms, as those working in a damp or cold environment had a greatly increased risk of having symptoms. Although in some of the reported occupations, damp or cold conditions may be unavoidable - for example, farm worker, gardener, bricklayer, police officer, armed forces-this may not be necessarily so in other occupations. The observed relations were not confounded by the actual tasks being carried out or psychosocial aspects of work.

Why should the increased risks in men noted for specific working conditions or activities not also have been found among women? It seems unlikely that, given a similar exposure to working tasks and working conditions, the risk of shoulder pain and disability is substantially lower among women. For most activities and adverse working conditions the number of women exposed was nearly always considerably smaller than the number of men exposed. This, however, does not explain the absence of observed risk, but only results in a greater uncertainty about the exact magnitude of risk about a point estimate (wide confidence intervals). Instead the risk found in women for a variety of exposures are consistently close to those in unexposed women. An explanation for these findings may be that, even when undertaking activities such as carrying weights on one shoulder, working with hands above shoulder level, or working in damp or cold conditions, the degree of exposure-for example, weights carried-was lower for women than for men. An alternative possibility is that other causes of shoulder pain are more important in women and so the impact of occupational exposure is less.

Among both men and women, a job that was reported as stressful had about double the risk, and one reported as monotonous had about three times the risk of shoulder pain. Stress at work has been reported in cross sectional studies to be associated with the occurrence of shoulder or neck symptoms, ${ }^{151819}$ and in two longitudinal studies to be predictive of future symptoms, ${ }^{2021}$ whereas other studies have failed to find a relation. ${ }^{22} 24$ The most consistent associations with symptoms in the shoulder region have been reported with "demand and control" psychosocial variables-for example, monotonous work, time pressure, highly perceived work load, or low control or autonomy. These studies have been conducted in different settings, with different study designs (cross sectional, case-control, 
and prospective) and with a variety of outcome variables (self reported symptoms, medical practitioner diagnosis, sick leave)..$^{1520232526}$ It is possible that the relation between psychosocial variables and shoulder symptoms is confounded by physical exposure variables. For example, variables such as lifting heavy weights, repetitive movements of the arm, and working in cold or damp conditions, as well as being risk factors for shoulder pain, might also be related to monotonous or stressful work. However, examining this hypothesis in the current study showed that, in men, even after physical exposure variables were accounted for, the relation between psychosocial variables and shoulder pain still existed. In women no such relation with physical exposures was found and therefore cannot be an explanation for the relation with psychosocial variables.

The current study is one of few to be population based and not confined only to those who have sought care for shoulder symptoms. It is therefore less likely to be affected by bias in recall of exposures than studies conducted in industrial settings. However, only two thirds of those eligible to participate returned the posted questionnaire and a further quarter of these did not agree to a subsequent interview. Those who did not return the posted questionnaire were more likely to be men and of younger age. From a review of general practitioner records it was found that these people were also less likely to have consulted the general practitioner in the previous two years with shoulder problems than those who returned the questionnaire. ${ }^{27}$ Those people who refused a subsequent interview did not differ in their reported experience of shoulder symptoms from those who were interviewed. However, the main findings of our study would change only if the relation between work exposures and shoulder pain differed between participants and non-participants and there is no reason for supposing that this was the case.

Many of the studies which have been conducted on occupation and shoulder problems have been cross sectional and therefore relate occupational exposures at the time of interview to current shoulder symptoms. This has the disadvantage that subjects may have changed occupation or work activities as a result of persistent shoulder problems. This leads to the phenomenon of the healthy worker effect whereby those prone to illness may have left an occupation carrying a high risk of illness and results in an underestimate of the true risk of disease associated with the occupation. This study, although cross sectional in design, has recorded a lifetime occupational history so that occupation and related activities, working conditions, and psychosocial factors at the time of initial onset of symptoms, could be determined. Finally recall bias, whereby cases are more likely to recall specific exposures than controls, can be an important problem for epidemiological studies. It is unlikely to have influenced the current results as a lifetime occupational history was obtained and this information was gathered separately from information on symptoms.
In summary, this population based study has shown that physical activities carried out at work, the physical conditions under which the work is conducted, and psychosocial aspects of work or the working environment are all related to the occurrence of shoulder symptoms and disability. Each has an independent effect on the risk of shoulder symptoms, emphasising the multifactorial aetiology of shoulder pain. These findings parallel those reported for occupational influences on low back pain, ${ }^{28}$ in which physical tasks, physical conditions, and psychosocial factors have been found to be important in predicting future occurrences of symptoms. As musculoskeletal disorders are the overall leading cause of occupational disability, ${ }^{29}$ effective measures to reduce the frequency of occurrence would have a significant financial implication for industry. Although emphasis in prevention programmes to date has been on the effect of heavy physical work, it is clear that this should not be considered in isolation from working conditions and environment.

We thank Dr Marshall, Michelle Martin, the staff, and patients of the general practice in Stockport, Greater Manchester. The manuscript was prepared with the assistance of Lesley Jordan, University of Manchester. The study was supported by the Arthritis and Rheumatism Council for Research, Chesterfield, United Kingdom.

1 Hadler NM. The roles of work and of working in disorders of the upper extremity. Baillière's Clin Rheumatol 1989;3: $121-41$.

2 Cunningham LS, Kelsey JL. Epidemiology of musculoskeletal impairments and associated disability. $\mathrm{Am} \mathcal{F}$ Public Health 1984;74:574-9.

3 Silverstein BA. The prevalence of upper extremity cumulative trauma disorders in industry [PhD thesis]. Ann Arbor: trauma disorders in industry
University of Michigan, 1985.

4 Sommerich CM, McGlothlin JD, Marras WS. Occupational risk factors associated with soft tissue disorders of the shoulder: a review of recent investigations in the literature. Ergonomics 1993;36:697-717.

5 Bongers PM, de Winter CR, Kompier MAJ, Hildebrandt VH. Psychosocial factors at work and musculoskeletal disease. Scand $\mathcal{F}$ Work Environ Health 1993;19:297-312.

6 Patrick DL, Peach H. Disablement in the community. Oxford: Oxford University Press, 1989.

7 Croft PR, Pope D, Zonca M, O'Neill T, Silman AJ. Measurement of shoulder related disability: results of a validation study. Ann Rheum Dis 1994;53:525-8.

8 Papageorgiou AC, Croft PR, Ferry S, Jayson MIV, Silman AJ. Estimating the prevalence of low back pain in the Aj. Estimating the prevalence of low back pain in the general population: evidence from the South
back pain survey. Spine 1995;20:1889-94.

9 Osborne J, Cattaruzza $M$. Odds ratio and relative risk for cross-sectional data. Int 7 Epidemiol 1995;24:464-5.

10 Stata Corporation. Stata reference manual: release $3 \cdot 1$ th ed. College Station, Texas: Stata, 1993.

1 Wells JA, Zipp JF, Schuette PT, McEleney J. Musculoskeletal disorders among letter carriers. F Occup Med 1983;25:814-20.

12 Hagberg M, Wegman DH. Prevalence rates and odds ratios of shoulder-neck diseases in different occupational of shoulder-neck diseases in differen.

13 Holmstrom EB, Lindell J, Moritz U. Low back pain and neck/shoulder pain in construction workers: occupational workload and psychosocial risk factors. Part 2: relationworkload and psychosocial risk factors. Part 2: relation-
ship to neck and shoulder pain. Spine 1992;17:672-7.

14 Stock SR. Workplace ergonomic factors and the development of musculoskeletal disorders of the neck and upper ment of musculoskeletal disorders of the neck and upper

15 Kvarnström S. Occurrence of musculoskeletal disorders in a manufacturing industry with special attention to occupational shoulder disorders. Scand $\mathcal{F}$ Rehabil Med 1983; (suppl 8): 1-114

16 Gemne G, Saraste $H$. Bone and joint pathology in workers using hand-held vibrating tools: an overview. Scand $\mathcal{F}$ Work Environ Health 1987;13:290-300

17 Burdorf A, Monster A. Exposure to vibration and selfreported health complaints of riveters in the aircraft industry. Ann Occup Hyg 1991;35:287-98.

18 Ohara $H$, Nagagiri $S$, Itani $T$, Wake $K$, Aoyama $H$ Occupational health hazards resulting from elevated work rate situations. F Hum Ergol 1976;5:173-82.

19 Ohlsson K, Hansson G-A, Balogh I, Stromberg U, Palsson B, Norlander C, al Disorders of limbs in women in the fish processing industry. Occup 
Environ Med 1994;51:826-32.

20 Veiersted KB, Westgaard RH. Work related risk factors fo trapezius myalgia. In: Hagberg M, Kilbom A, eds. Book of abstracts of the International Scientific Conference on Prevention of Work-Related Musculoskeletal DisordersSweden 1992. Stockholm: Arbetarskyddsverket, 1992.

21 Leino P, Magni G. Depressive and distress symptoms as predictors of low back pain, neck-shoulder pain, and predictors of low back pain, neck-shoulder pain, and other musculoskeletal morbidity: a 10-year foll
metal industry employees. Pain 1993;53:89-94.

22 Bergenudd $\mathrm{H}$, Lindgärde $\mathrm{F}$, Nilsson B, Petersson CJ Shoulder pain in middle age: a study of prevalence and relation to occupational work load and psychosocial fac-

23 Linton SJ, Kamwendo K. Risk factors in the psychosocial work environment for neck and shoulder pain in secretaries. F Occup Med 1989;31:609-13.

24 Kamwendo K, Linton SJ, Moritz U. Neck and shoulde disorders in medical secretaries: part II, ergonomic work environment and symptom profile. Scand $\mathcal{F}$ Rehab Med 1991;23:135-42.

25 Linton SJ. Risk factors for neck and back pain in a working population in Sweden. Work Stress 1990;4:41-9.

26 Toomingas A, Theorell T, Michélson H, Nordermar R. Associations between perceived psychosocial job factors and prevalence of musculoskeletal disorders in the neck and prevalence of musculoskeletal disorders in the neck and shoulder regions. In: Hagberg $M$, Kilbom $A$, eds Book of abstracts of the International Scientific Conference on Prevention of Work-Related Musculoskeletal Disorders
Sweden 1992. Stockholm: Arbetarskyddsverket, 1992.

27 Pope D, Croft P. Surveys using general practice registers: who are the non-responders? f Public Health Med 1996; 18:6-12.

28 Skovron ML. Epidemiology of low back pain. Baillière's Clin Rheumatol 1992;6:559-73.

29 Putz-Anderson V, ed. Cumulative trauma disorders: a manual for musculoskeletal diseases of the upper limbs. London Taylor and Francis, 1988 